\title{
Popularization of shooting sports as a means of introducing young people to a healthy lifestyle
}

\author{
Olga Moiseeva ${ }^{1, *}$, Olga Filippova ${ }^{1}$, and Egor Moiseev² \\ ${ }^{1}$ Moscow State University of Technologies and Management named after K.G. Razumovsky (the First \\ Cossacs University), 73 Zemlyanoy Val, 109004 Moscow, Russian Federation, \\ ${ }^{2}$ Russian State University of Physical Education, Sport, Youth and Tourism (SCOLIPE) Federal State \\ Budgetary Educational Establishment of Higher Education, 4 Sireneviy Boulevard, 105122 Moscow, \\ Russian Federation
}

\begin{abstract}
In modern society, the problem of value orientation of young people to a healthy lifestyle is discussed. Today, the importance of a healthy lifestyle is recognized as a factor of the national security of the state. Introduction to a healthy lifestyle is possible through sports. Often young people, realizing the need to lead a healthy lifestyle, refuse to participate in sports life for fear of failure, lack of the necessary physical ability. Therefore, the popularization of shooting sports, in our opinion, should be aimed at involving young people who may not have succeeded in other sports. The attractiveness of shooting sports is also evident in the fact that there are no strict age limits. It is necessary to analyze the existing approaches to the popularization of shooting sports by the Shooting Sports Federation of Russia (SSR) to identify ways to increase interest in these sports among young people.
\end{abstract}

\section{Introduction}

Shooting sports are one of the most ancient sports. Shooting as a human activity originated to provide primitive people with food. And only then there was a competitive component to test the accuracy of the eye, the firmness of the hand, and the range of flight. For a young person, this sport is a school of tempering character, which forms determination, perseverance, a sense of teamwork, and the ability to adapt to circumstances. Bullet shooting, like no other sport, contributes to the development of attention, emotional stability, and strong-willed efforts. In addition to all the above, shooting sports are also necessary for young men in the case of military service.

The main goal of the Shooting Union of Russia is to develop, promote, and popularize shooting sports. Currently, the issue of popularizing the shooting sport is on the agenda not only due to the attention and support from the state but also due to the stricter requirements for the authorization of the issue of weapons. In our opinion, the involvement of young people in shooting sports will help to form young people's respect for this sport and responsibility for the use of weapons, create conditions for studying the law of the Russian Federation "On Weapons" and a conscious attitude to its use.

${ }^{*}$ Corresponding author: MoiseevaOA@mgutm.ru 
"Shooting sports are one of the most medal-intensive sports in both Olympic and nonOlympic disciplines. Our champions actively defend the honor of Russia on the global stage. The country should know the heroes. They should be an example for the younger generations, inspire juniors to sports feats," said Pavel Novikov, Deputy Minister of Sports of the Russian Federation, at a meeting dedicated to the promotion of shooting sports [1].

The promotion of shooting sports, in our opinion, should also be aimed at involving young people who may not have succeeded in other sports. Shooting competitions do not require a competitor to be the fastest, tallest, or strongest. All that is required is patience, determination, organizational skills, mental and physical control, safety awareness, goal setting, problem-solving, and sports prowess. [2]

\section{Materials and methods}

Within the framework of the project "Promotion of the Shooting Union of Russia", an analysis of the activities of this sports federation and a sociological survey among young shooting athletes was conducted. Sports events socialize the younger generation, orient them to a healthy and socially active lifestyle. The achievements of our country in sports have a significant impact on the formation of patriotic views and worldviews of young people and schoolchildren [3]. Shooting sports with a long tradition in Russia and the world have prospects for involving a significant part of the population of all ages.

Before analyzing the sociological survey, the official website of Shooting Sports in Russia was analyzed using Yandex.Metrica technology, a free Internet service owned by Yandex. This service is designed both to evaluate website traffic and to analyze the behavior of website visitors.

According to Yandex.Metrica, the official website of the Shooting Union of Russia had 41,922 visitors in the last quarter of 2020.

After studying the sources and the main ways to get visitors to the website (see Figure 1 ), it should be noted that more than $90 \%$ of traffic to the official website occurs through direct visits (46.1\%), traffic from search engines (33.3\%), and internal traffic (17.7\%). And traffic from public networks and traffic from links on other websites accounts for only $2.89 \%$. Thus, SMM promotion and contextual advertising, which are very popular with the Shooting Union, do not develop, cutting off the youth audience (Figure 2).
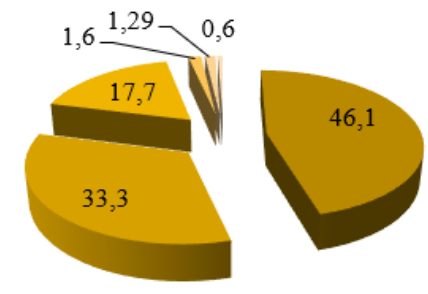

Direct visits

Traffic from search

networks

Internal traffic

\raffic from social networks

Fig.1. Sources of the official website of the Shooting Union of Russia, \%

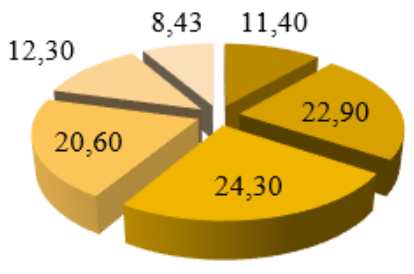

$$
\begin{aligned}
& \text { 18-24 years old } \\
& 25-34 \text { years old } \\
& 35-44 \text { years old } \\
& 45-54 \text { years old } \\
& 55 \text { years and older }
\end{aligned}
$$

Fig. 2. Age of visitors to the official website of the Shooting Union of Russia, \% 
In October 2020, the Brand Analytics analytical center conducted a regular study of the active audience of social networks in Russia [3]. According to the study, the number of active authors was 64 million, who wrote more than 1.2 billion public messages (posts, reposts, comments). The number of authors and posts for each social network enables to assess the popularity of websites among Russian users (see Figure 3).

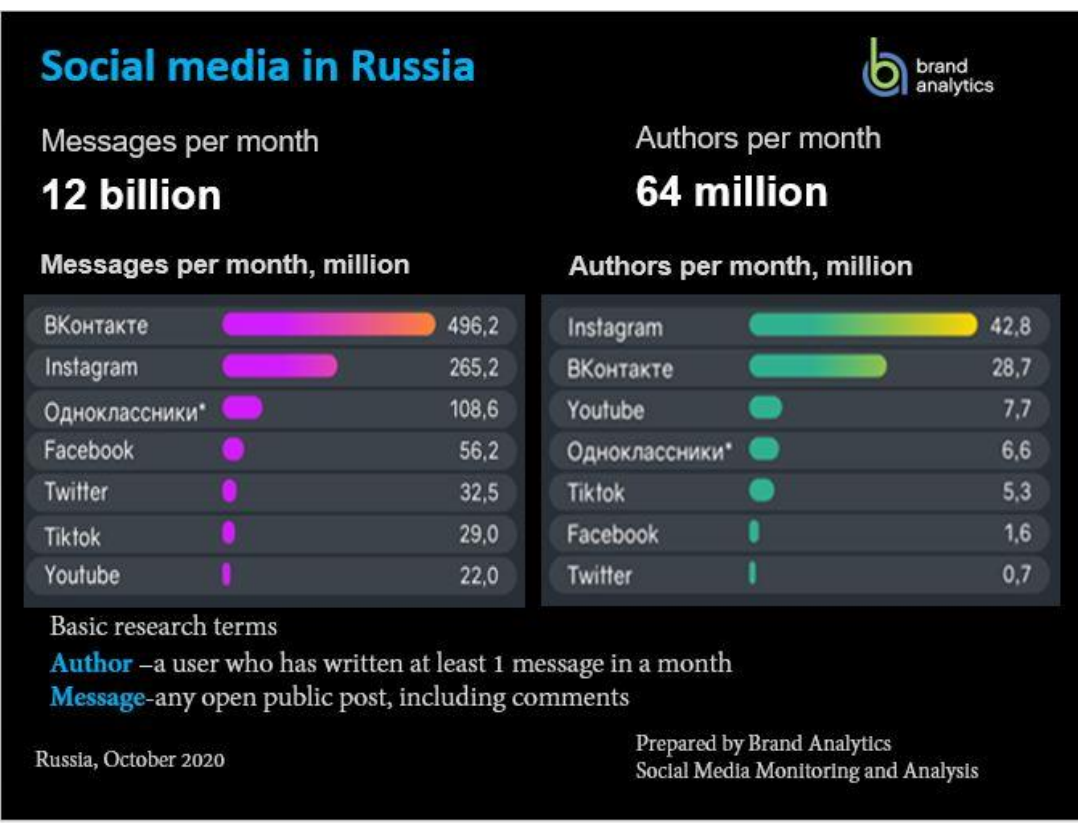

Fig. 3. Number of authors and posts for each social network

ВКонтакте (496.2 million posts per month and 28.7 million authors) and Instagram (265.2 million posts per month and 42.8 million authors) remain among the most popular social networks among Russian users. At the same time, TikTok was included in the study for the first time, ahead of Youtube in terms of content volume, and Facebook and Twitter in terms of the number of authors.

Among active authors, the largest male audience is on Twitter and YouTube $(60.3 \%$ and $58 \%$, respectively), the largest female audience is on Instagram (77\%), slightly less on Facebook (60\%). Tiktok and ВКонтакте have relative equality (see Figure 4).

Many social networks do not have age information, so the Brand Analytics study only partially presents this data for Facebook and ВКонтакте. On ВКонтакте, the main age of the audience is $25-34$ years (30.8\% of the audience), then comes 18-24 (20\%) and 35-44 (19\%) groups. On Facebook, the majority of the audience is over 25 and under 54. 


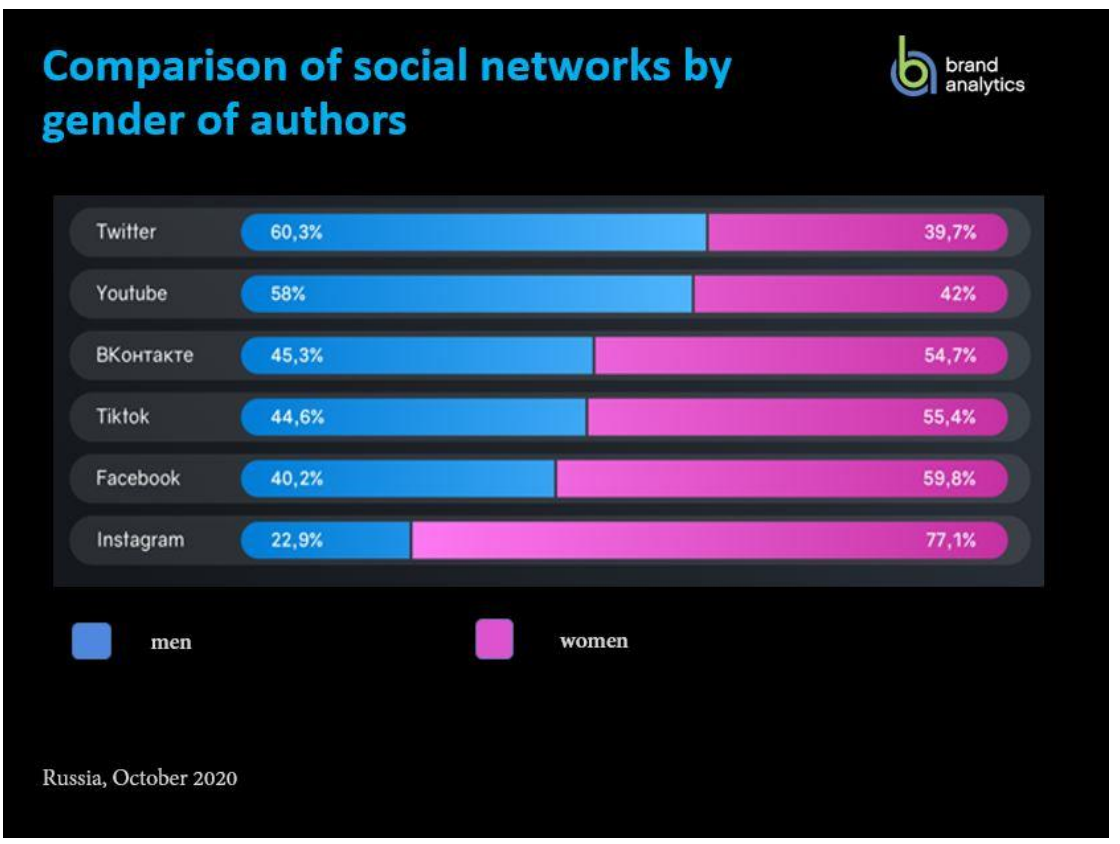

Fig. 4. Comparison of social networks by gender of authors.

Summing up the results of the research conducted by the Brand Analytics analytical center, it can be noted that the most successful social networks for SMM promotion in Russia are ВКонтакте and Instagram, and TikTok, which is gaining popularity.

The sociological survey conducted in the framework of our research will help to identify the current attitude among athletes to the Shooting Union of Russia and its support on the Internet.

The purpose of the survey was to analyze the interest of shooters in the Shooting Union of Russia and its competitions and events.

Objectives:

1) to find out the level of interest among athletes in sports events and competitions;

2) to analyze the sources from which the shooters would like to receive information;

3 ) to study the attitude of shooters to the official website of the Shooting Union of Russia.

The survey was conducted in social networks in groups dedicated to shooting sports. The respondents were athletes engaged in shooting sports and members of shooting groups. The survey involved an almost equal ratio of men and women in shooting sports. Age group ratio: under 14 years $-11.1 \% ; 15-18$ years $-27.8 \% ; 18-22$ years $-38.9 \%$; $23-28$ years $-5.6 \% ; 29-35$ years $-5.6 \%$. It is worth noting that the number of athletes over 55 years old was very small, but most likely they are not interested in taking this survey.

The questionnaire was an original author's questionnaire, specially created for this study. The questionnaire was structured from general to specific. The hard data contained research filters based on gender and age. The first block of questions was focused on understanding the research topic, how much the respondent was involved in it, and was aimed at assessing the understanding of shooting sports in general. The second block was intended to reveal the attitude of athletes to the Internet support of the Shooting Union of Russia. The final block of questions was aimed at studying the opinion of athletes about the popularity and popularization of shooting sports. 


\section{Results and discussion}

As a result, the following data was obtained.

When asked about the reason for joining the shooting sport, the majority of respondents (39.1\%) answered that they themselves were interested in this sport, $34.8 \%$ of respondents were brought by friends. Answers "Teacher advised" and "Brought by parents" were chosen by $8.7 \%$ of the respondents.

The majority of respondents (43.5\%) have been engaged in shooting sports for 1 to 5 years. $24.8 \%$ have just come to this sport, and $31.7 \%$ have been in sports for more than 5 years, of which $13 \%$ have been in sports for more than 10 years.

$62.2 \%$ of respondents follow shooting sports competitions, while $33.3 \%$ of them do it all the time. The vast majority of respondents $(70.8 \%)$ are interested in the events held by the Shooting Union of Russia.

The question "How do you track shooting sports competitions?" showed the following results. Among the respondents, $25 \%$ personally go to competitions as participants or spectators. Also, $25 \%$ only check the results on the official website of the Shooting Union. The majority $(33.3 \%)$ prefer to follow the competitions through social networks. Among traditional media, $8.3 \%$ of respondents prefer television. $8.3 \%$ of respondents are not interested in competitions.

Among the desired sources of information about the events of the Shooting Union of Russia, almost half of the respondents $(45.8 \%)$ favored social networks. The official website of the Shooting Union as the main source of information was chosen by only $20.8 \%$ of respondents, and the same number of respondents would prefer to receive information through an e-mail newsletter.

Half of the respondents have a positive attitude to the official website of the Shooting Union of Russia, while $29.2 \%$ said that they did not care about it.

It is worth noting that only $8.3 \%$ of respondents visit the official website of the Shooting Union every day. $27.8 \%$ do this every week. $16.7 \%$ visit the website every month, the same number of respondents visit the website less than once a month, and the same number have never visited it. The main purpose of the visit is to learn the latest news of the Shooting Union of Russia (38.9\%). 22.2\% study the results of the competition, $16.7 \%$ watch photos and videos from the competition and another $12.5 \%$ of respondents learn the schedule of the competition.

Thus, it becomes clear that almost all athletes follow the competitions and events through social networks, and the official website is mostly visited no more than once a week to get information about the events that have already taken place.

The vast majority of respondents $(62.5 \%)$ believe that shooting sports are not popular in Russia. According to respondents, the main reason for the unpopularity of shooting sports is associated with low media coverage, so $41.7 \%$ of respondents thought. $89.5 \%$ of respondents want to popularize shooting sports.

As a result, we can note the fact that respondents understand that shooting sports are not popular, and they want this to be changed.

\section{Conclusion}

Summing up the analysis of public opinion, Yandex.Metrica statistics, and data from the Brand Analytics analytical center, it is worth noting that the Internet support of the Shooting Union should be aimed at young people [5]. The most suitable social networks for Internet support are ВКонтакте and Instagram, which are the most popular networks among respondents according to data obtained from the Brand Analytics analytical center. At the same time, an analysis of the website of the sports federation showed that the 
Shooting Union of Russia has accounts on Instagram, Facebook, but does not have an account on ВКонтакте, although the majority of young athletes surveyed communicate through this social network and are subscribers of such popular communities as "Weapon of Humanity" (2.7 million subscribers), "Olympic Games" (2.3 million subscribers), "Sale of Shooting Clothing and Equipment" (6,524 subscribers), "Experimental Masters of Sports" (2,637 subscribers) and others local groups.

According to the study, the majority of respondents came to shooting sports on the advice of a friend or out of their own interest. Most of the respondents follow the shooting sports competitions and events held by the Shooting Union of Russia. From which it follows that if we raise loyalty among athletes, they may bring their friends and acquaintances to the shooting sport, which in turn will help to popularize it [6].

It should be noted that in turn, parents, bringing their children to the sections, show interest in this sport and start classes.

It was also revealed that the respondents are aware of the problem of the unpopularity of shooting sports in the Russian Federation and they want this to be changed.

From all of the above, we can conclude the following:

1. Young people and the younger generation are eager for interesting and diverse activities. Many people want to go in for sports, but by the time their conscious choice can take place, the time for admission to professional sports sections passes. And in shooting sports, they can become professional athletes, regardless of the age at which they started practicing $[6,7]$.

2. Modern culture and cinema, increasingly using shooting scenes, promotes shooting sports [8].

3. It is shooting sports that can become a family hobby, strengthen relations between generations, and intensify communication between family members [9].

Thus, even though the popularization of shooting sports is the stated goal of the sports federation, in our opinion, modern methods of Internet promotion in social networks are not fully used to achieve it. The creation of the federation's account in the social network ВКонтакте in collaboration with manufacturers of sports equipment would make it possible to solve the problem of involving young people in shooting sports more effectively.

\section{References}

1. The Ministry of Sports of Russia held a meeting on the creation of Russian shooting sports equipment and the popularization of shooting sports, https://minsport.gov.ru

2. O. N. Savinkova, M. M. Kublanov, Materials of the III All-Russian Scientific and Practical Conference with International Participation dedicated to the 40th anniversary of the VGIFK (2019)

3. I. N. Sycheva, O. V. Chernyshova, T. A. Panteleeva, S. A. Chernyavskaya, S. Y. Khout, International Journal of Economics and Business Administration, 7, 595 (2019)

4. V. Cherny, Brand Analytics (2020) https://br-analytics.ru

5. O. Moiseeva, O. Filippova, I. Polozhentseva, V. Ponomarev, R. Rabadanova, Employee Image in Social Media As A Promotion Tool (2021)

6. A. S. Zotova, S. V. Kondratiev, O. A. Moiseeva, O. A. Filippova, Psychology of mass communication, Moscow, Buki-Vedi (2019)

7. S. V. Dmitrichenkova, T. G. Stanchuliak, M. B. Budiltseva V. S. Bereznyakovsky, I. K. Orlova, O. A. Filippova, O. A. Moiseeva, Training the Modern Manager in the Context of the Competence Approach (2019) 
8. A. S. Zotova, O. A. Moiseeva, O. A. Filippova, Communication in modern media discourse, Vladimir, Kaleidoscope (2019)

9. V. N. Novikova, Materials of the III All-Russian Conference of International Participation dedicated to the 40th anniversary of the VGIFK, 232 (2019) 